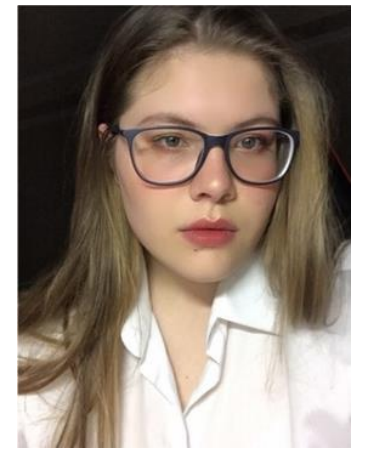

\section{ЭКОНОМИКА КИТАЯ В СИСТЕМЕ МИРОВОГО ХОЗЯЙСТВА}

\author{
Д. С. Рокина, студентка 1-го курса, \\ e-mail: dasharokina01@gmail.com \\ ФГБОУ ВО «Калининградский государственный \\ технический университет» \\ А. А. Котенко, канд. экон. наук, доц., \\ e-mail: aljona.kotenko@klgtu.ru \\ ФГБОУ ВО «Калининградский государственный \\ технический университет»
}

В статье рассмотрено изменение положения экономики Китая в системе мирового хозяйства, влияние Китая на международные экономические отношения, анализируется динамика индикаторов социально-экономического развития Китая за последние 30 лет, описываются методы борьбы с кризисом, предсказывается дальнейшее развитие Китая. Главное внимание обращается на так называемую авторами «формулу успеха», которая сделала Китай таким, какой он есть сейчас. Результаты исследования позволили авторам сделать вывод об укреплении положения Китая в системе мирового хозяйства.

Ключевые слова: новая модель глобализации, кризис, социально-экономические индикаторы, динамика ВВП, движение капитала, инвестиции, внешняя торговля, структура экономики, третичный сектор, международные резервы, «формула успеха»

\title{
ВВЕДЕНИЕ
}

В последние десятилетия произошло превращение Китая в одного из ведущих игроков мировой экономики. С одной стороны, его все более и более укрепляющаяся экономика оказывает влияние на мировое экономическое развитие, с другой - усиливается и влияние глобализационных процессов на экономику Китая. Безусловно, позиции ведущего игрока на мировой арене Китаю обеспечивает его экономическая мощь, место не только «мировой фабрики», но и источника глобального экономического роста. Феноменальные достижения Китая привлекают внимание исследователей, экспертов.

\section{ОБЪЕКТ ИССЛЕДОВАНИЯ}

Объектом исследования является экономика Китая, предметом - факторы, определяющие изменение положения экономики Китая в системе мирового хозяйства.

\section{ЦЕЛИ И ЗАДАЧИ ИССЛЕДОВАНИЯ}

Цель исследования состояла в определении роли экономики Китая в современной мировой экономике. Исходя из поставленной цели были определены следующие задачи: провести сравнительный анализ основных социально-экономических показателей экономики Китая за 1990-2020 гг.; изучить тенденции и особенности развития его экономики; обозначить перспективы развития экономики Китая и показать их влияние на систему мирового хозяйства.

\section{МЕТОДЫ ИССЛЕДОВАНИЯ}

В процессе исследования в работе применялись общенаучные и специальные методы: синтез и анализ научной литературы, количественный и качественный анализ, сравнение. Осуществлен анализ данных по экономике Китая, представленный такими международными экономическими организациями, как Всемирная торговая организация, Всемирный банк. 


\section{РЕЗУЛЬТАТЫ ИССЛЕДОВАНИЯ}

Новая модель глобализации, или же инициатива «Один пояс один путь», - самый масштабный проект инвестиций в управление инфраструктурой и логистикой, который видел мир. Проект не ограничен только строительством, он направлен и на массовое развитие экономических коридоров, на создание институциональных связей и устранение барьеров на пути сотрудничества между Китаем и экономическими сообществами, населяющими «мировой остров». К ним относят АCЕАН, возглавляемый Россией Евразийский экономический союз, Шанхайскую организацию сотрудничества, ЕС, Южноазиатскую ассоциацию регионального сотрудничества (СААРК) и Организацию исламского сотрудничества. Ключевым строительным блоком в этих усилиях является так называемое «региональное всеобъемлющее экономическое партнёрство» или RCEP. Это создаст зону свободной торговли, охватывающую Китай, АСЕАН, Австралию, Индию, Японию, Южную Корею и Новую Зеландию. Целью геоэкономической концепции является содействие его экономической интеграции с «мировым островом» - Евразией и Африкой. «Один пояс, один путь» охватывает три области экономического сотрудничества: инфраструктурное, производственное и финансовое. Его имплементация станет предпосылкой экономического развития, спроса на строительные материалы и прочие ресурсы, валютной стабильности [1].

Финансовый кризис 2008-2009 гг. был страшной экономической катастрофой со времен Великой депрессии 1929 г. Однако китайская экономика сумела преодолеть его последствия: уменьшение внешнего спроса, что стало предпосылкой снижения китайского экспорта, заставило власти обратиться к внутренним источникам экономического роста. И несмотря на кризис ВВП Поднебесной смог вырасти на 8 \%, в отличие от других стран. Для такого результата Правительство КНР разработало следующие «пути решения»: расширение потребительского рынка в стране, совершенствование структуры инвестиций центрального и местного бюджетов в экономику, развитие высокотехнологических инновационных проектов, снижение цен на жилье для малообеспеченных граждан и т. д. Главной частью программы правительства являются крупные инфраструктурные проекты (мосты, дороги, аэропорты, линии электропередач) [9]. Они создали дополнительные рабочие места, которые, в свою очередь, привели к энергетическому росту в разных отраслях экономики. Таким образом, Китай не только сохранил высокие темпы экономического роста ВВП, но и расширил внутренний спрос, позволяющий формировать «конкурентную среду» в стране.

Чтобы выявить особенности развития китайской экономики, проведем анализ основных социально-экономических показателей развития экономики Китая за 1990 и 2020 гг. (табл. 1).

С 1990 по 2020 г. произошли значительные изменения в общем состоянии общества Китая. ВВП в текущих ценах вырос в 41 раз в 2020 г. по сравнению с 1990 г. ВВП по ППС вырос в 21 раз и в 2020 г. китайская экономика стала первой экономикой мира, опередив США по этому показателю. Однако и численность населения республики выросла с 1135,2 тыс. чел. в 1990 г. до 1402,7 тыс. чел. в 2020 г. [11]. Поэтому важно рассмотреть динамику ВВП на душу населения: в 2020 г. был в 31 раз больше, чем в 1990 г.

Об укреплении позиций Китая на мировом рынке свидетельствует рост его доли в мировом продукте - с 4 \% в 1990 г. до 18,6 \% в 2020 г. Доля Китая в мировой товарной торговле выросла в 8 раз - с 1,5 \% в 1990 г. до 12,8 \% в 2019 г. по экспорту товаров и соответственно с 1,3 до 10,7 \% по импорту товаров (табл. 1). Производство в Китае становится более капиталоемким и высокотехнологичным. Так, число заявок на патенты выросло с 5832 в 1990 г. до 1442538 в 2020 г., т. е. почти в 250 раз! Можно предположить, что в ближайшем будущем Китай станет ведущим мировым производителем не только товаров, но и технологий. По индексу глобальной конкурентоспособности Китай в 2019 г. был на 27-м месте среди 141 страны. В 2006 г. Китай был 54-м из 125 стран по индексу конкурентоспособности [14]. 
Таблица 1 - Социально-экономические индикаторы развития Китая [10-14]

\begin{tabular}{|l|c|c|c|}
\hline \multicolumn{1}{|c|}{ Показатель } & 1990 г. & 2020 г. & $\begin{array}{c}\text { Темп } \\
\text { прироста, } \%\end{array}$ \\
\hline ВВП в текущих ценах, млрд. долл. США & 369,58 & 15222,16 & +4019 \\
\hline ВВП по ППС, млрд. долл. США & 1108,09 & 24162,44 & +2080 \\
\hline ВВП по ППС на душу населения, долл. США & 347 & 10839 & +3023 \\
\hline Доля в мировом производстве, \% & 4,03 & 18,6 & +361 \\
\hline Доля в мировом товарном экспорте, \% & 1,5 & 12,8 (в 2019 г.) & +753 \\
\hline Доля в мировом товарном импорте, \% & 1,3 & 10,7 в 2019 г.) & +723 \\
\hline Экспорт услуг, млрд. долл. США & 5,8 & 244,36 (в 2019 г.) & +4113 \\
\hline Импорт услуг, млрд. долл. США & 4,352 & $505,51($ в 2019 г.) & +11515 \\
\hline Заявки на патенты & 5832 & 1442538 & +24634 \\
\hline Уровень безработицы, \% & 66,3 & 5,2 & -92 \\
\hline Доля занятых в сфере услуг, \% & 18,3 & $46,4 \%$ & $+153,6$ \\
\hline Приток ПИИ, млрд. долл. США & 3,447 & 141 & \\
\hline ПИИ, чистый отток (\% от ВВП) & 0,2 & 0,7 & +250 \\
\hline $\begin{array}{l}\text { Международные резервы, включая золото, } \\
\text { млрд. долл. США }\end{array}$ & 34,5 & 3222,9 & +9241 \\
\hline Уровень инфляции, \% & & & \\
\hline Туризм, чел. & 3,1 & 2,9 & $-0,6$ \\
\hline & 46387000 & 162538000 & +250 \\
\hline ИЧР & $($ в 1995 г.) & $($ в 2019 г.) & \\
\hline Индекс экономической свободы & 0,5 & 0,76 & +52 \\
\hline Индекс глобальной конкурентоспособности & 52 (в 1995 г.) & 59,5 & +14 \\
\hline Рейтинг восприятия коррупции (чем ближе к & 35 & 73,9 & +1430 \\
\hline 100, тем лучше) & & 42 & +20 \\
\hline Простота ведения бизнеса & 53,12 (в 2016 г.) & 77,93 & +23 \\
\hline Индекс процветания LЕGАТUМ & 54,51 & 61,49 & +13 \\
\hline Уровень счастья & 4,98 & 5,34 & +7 \\
\hline
\end{tabular}

Проводимые в последние четверть века экономические и политические реформы, либерализация экономической деятельности привели к улучшению делового климата в Китае. Оценка институциональных изменений говорит о прогрессе в этой сфере: выросли индексы экономической свободы, простоты ведения бизнеса, неприятия коррупции (табл. 1).

Благодаря данному сравнению мы можем убедиться в социально-экономическом росте страны. Несмотря на улучшение социально-экономического состояния Китай всё же остаётся развивающейся страной. В нем преобладают бедные районы, присутствует дисбаланс экономического роста: прибрежные районы демонстрируют устойчивое развитие, в то время как другие - отстают. С 2012 г. уровень бедности в Китае упал с 10,2 до 0,6 \% в 2019 г. Кажется, что всё хорошо, однако уровень дохода на душу населения все еще ниже среднего мирового уровня. По мнению профессора Чжу Лицзя, показатель ВВП на душу населения для развитых стран должен достигать до 12700 долл., а для высокоразвитых экономик - до 40000 долл. [9]. Показатель Китайского ВВП на душу населения гораздо ниже этой отметки - 10839 долл. США (табл. 1).

Развитие современного мирового хозяйства в целом и национальных экономик в частности происходит в направлении постиндустриализации. В развитых странах доля сферы услуг в ВВП увеличивается, соответственно растет занятость населения в этой сфере. На рис. 1 видно, что доля первичного сектора в китайской экономике сократилась с 40,2 \% в 1990 г. до 4,2 \% в 2018 г., доля третичного сектора экономики возросла с 20 \% в 1990 г. до $57,7 \%$ в 2018 г.

Однако по показателю доли третичного сектора в экономике страны Китай значительно отстает от развитых стран - $78 \%$ он занимает в экономике США, $70 \%$ - в Японии, 66,8 \% - в Великобритании, 64,4 \% - в Германии [14]. Доля занятых в сфере услуг в 
китайской экономике возросла с 18,3 до 46,4 \% (табл. 1) и по этому показателю Китай также отстает от развитых стран: в Великобритании в сфере услуг занято $81,1 \%$ населения, в США $-78,7$, в Японии - 72,3, в Германии - 71,8 \% [14].

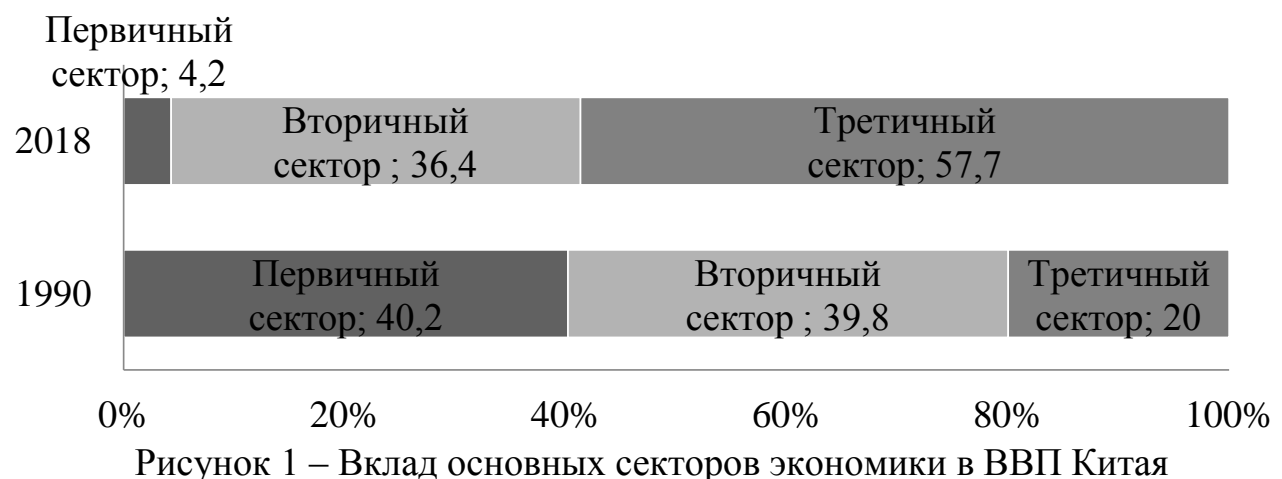

Растет доля Китая в мировом экспорте услуг. Экспорт услуг с 1990 года увеличился в 42 раза (табл. 1). В 2019 г. Китай занимал шестое место в мире по объему оказанных услуг. В 2018 г. был на пятом месте (табл. 2). По объему импорта услуг Китай еще в 2014 г. вышел на второе место в мире после США (табл. 2).

Таблица 2 - Ведущие экспортеры и импортеры услуг в мировой экономике[11]

\begin{tabular}{|c|c|c|c|c|}
\hline \multirow{2}{*}{ Место } & \multicolumn{2}{|c|}{ Экспорт } & \multicolumn{2}{|c|}{ Импорт } \\
\hline & 2018 & 2019 & 2018 & 2019 \\
\hline 1 & США & США & США & США \\
\hline 2 & Великобритания & Великобритания & Китай & Китай \\
\hline 3 & Германия & Германия & Германия & Германия \\
\hline 4 & Франция & Франция & Франция & Ирландия \\
\hline 5 & Китай & Ирландия & Великобритания & Великобритания \\
\hline 6 & Ирландия & Китай & Ирландия & Франция \\
\hline 7 & Индия & Индия & Япония & Япония \\
\hline 8 & Сингапур & Япония & Сингапур & Сингапур \\
\hline 9 & Нидерланды & Сингапур & Нидерланды & Нидерланды \\
\hline 10 & Япония & Нидерланды & Южная Корея & Южная Корея \\
\hline
\end{tabular}

Наиболее быстрыми темпами по сравнению с другими странами растет экспорт строительных услуг из Китая (рис. 3). В последнее десятилетие страна проявила себя как глобальный экспортер строительных услуг крупных инфраструктурных строительных проектов. Доля Китая в мировом экспорте строительных услуг в 2017 г. составил 37,3\%, $(8,4 \%$ в 2005 г.). В результате Китай стал вторым по величине экспортером в этом сегменте в мире после Евросоюза. Китайские фирмы активны в строительстве мостов, гаваней, автомобильных и железных дорог в Африке и в других развивающихся регионах. В строительной отрасли Китая ожидается дальнейший рост экспорта с появлением «Пояса» и программы «Дорожная инициатива», запущенной в 2013 г. китайским правительством с целью развития инфраструктуры в своей стране и инвестиций во многих странах.

В четвертом квартале 2020 г. рост ВВП Китая составил 6,5 \%, что помогло довести годовой рост китайского ВВП до 3,29 \%. Такая динамика может позволить КНР стать первой экономикой мира, опередив США раньше, чем прогнозировалось. В прошлом году Китай был единственной ведущей экономикой мира, которая по итогам 2020 года выросла, несмотря на негативное влияние пандемии коронавируса и масштабных карантинных мер (табл. 3). 


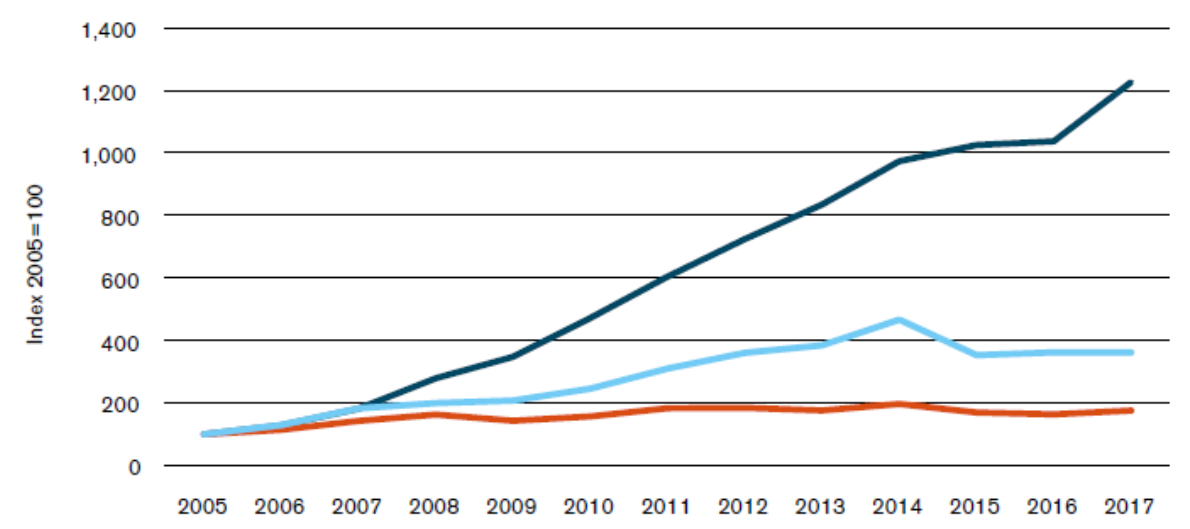

China $\simeq$ Developed economies $\rightleftharpoons$ Other developing economies and LDCs

Рисунок 3 - Динамика объемов экспорта услуг строительства в мире [13]

Таблица 3 - Динамика ВВП по ППС, млрд. долл. США [11]

\begin{tabular}{|l|c|c|c|c|c|}
\hline \multicolumn{1}{|c|}{ Страна } & 2020 & 2019 & 2018 & 2017 & 2016 \\
\hline Китай & 24162,44 & 23393,00 & 21659,30 & 19814,06 & 18701,70 \\
\hline США & 20807,27 & 21433,23 & 20611,88 & 19542,97 & 18745,10 \\
\hline Индия & 8681,3 & 9542,25 & 8998,69 & 8280,93 & 7735,00 \\
\hline Япония & 5236,14 & 5460,65 & 5319,35 & 5180,35 & 5076,06 \\
\hline Германия & 4454,50 & 4672,01 & 4564,72 & 4404,87 & 4164,75 \\
\hline $\begin{array}{l}\text { Российская } \\
\text { Федерация }\end{array}$ & 4021,73 & 4135,99 & 4009,65 & 3818,78 & 3538,58 \\
\hline
\end{tabular}

16.04.2021 американский финансово-экономический журнал «Forbes» выпустил новость о том, что рост китайского ВВП в первом квартале текущего года составил 18,3\% [5]. Это самый большой скачок валового внутреннего продукта с тех пор, как Китай начал вести квартальные записи в 1992 г. Однако к концу года прогнозируется снижение темпов.

Серьёзным предметом спора между экономистами всего мира стали перспективы экономики Китая. Прогнозируется, что ВВП Поднебесной к 2035 удвоится. С одной стороны, это невозможно, а с другой - цель достижима, ибо Китай - страна с высоким уровнем готовности к выполнению порой непосильных задач. Доклад Royal Bank of Canada «Влияние мира на Китай» предсказывает, что к 2030 г. КНР войдет в ряд стран с высоким уровнем дохода, а уже к 2025 г. процветание Китая увеличится в 4 раза [4].

Внешнеторговая политика КНР ориентирована на высокие темпы прироста ВВП и увеличение объемов экспорта в мировой торговле, что позволяет стране продуцировать 18,6 \% мирового ВВП и $10 \%$ мирового экспорта.

Сегодня Китай - активный участник международных инвестиционных отношений. До 1993 г. он мало участвовал в этом процессе, ежегодные потоки как в страну, так и из неё не превышали 10 млрд. долл. США. После 2004 г. Китай стал одним из лидеров мирового движения капитала с ежегодными потоками его вывоза и ввоза (табл. 4) - второе место в 2019 г. после США. Прямые иностранные инвестиции в экономику Китая в 2020 г. достигли рекордных 999,98 млрд. юаней, о чем сообщает Министерство торговли КНР. Одна из главных причин - пандемия. Китай был первой страной, которая « ...быстро обуздала вспышку, быстро перезапустила работу и производство, быстро достигла экономического роста, - говорил глава Национального бюро статистики (НБС) Нин Цзичже. - к следующим причинам можно отнести стабильность, ёмкий внутренний рынок, дешёвую рабочую силу, предоставление льгот и прочих видов поддержки частным компаниям». 
Таблица 4 - Ввоз ПИИ (млрд. долл. США) [12]

\begin{tabular}{|l|c|c|c|c|c|c|c|}
\hline \multicolumn{1}{|c|}{ Страна } & 2000 & 2014 & 2015 & 2016 & 2017 & 2018 & 2019 \\
\hline Китай & 41,0 & 129 & 136 & 134 & 136 & 138 & 141 \\
\hline США & 301 & 107 & 380 & 457 & 275 & 254 & 246 \\
\hline Великобритания & 117 & 52 & 40 & 196 & 100 & 65 & 59 \\
\hline Франция & 43 & 15 & 43 & 35 & 50 & 38 & 34 \\
\hline Германия & 195 & 1 & 32 & 17 & 35 & 74 & 36 \\
\hline Канада & 67 & 59 & 49 & 27 & 24 & 43 & 50 \\
\hline Мексика & 15 & 26 & 30 & 30 & 30 & 35 & 33 \\
\hline
\end{tabular}

В 2016 г. Китай стал вторым по величине иностранным прямым инвестором в мире, что послужило продолжению увеличения внешних потоков иностранных инвестиций в Китай. Внешние ПИИ Поднебесной обусловлены государственными предприятиями, стремящимися к стратегическим активам и природным ресурсам, а также частными предприятиями, стремящимися ослабить давление от роста внутренних затрат на рабочую силу. Азиатские страны являются крупнейшими получателями китайских ПИИ. Хотя их увеличение открывает возможности для развивающихся стран, необходимы двусторонние и многосторонние переговоры для решения таких вопросов, как доступ к рынкам и озабоченность принимающих стран по поводу недобросовестной конкуренции и национальной безопасности.

На мировую экономику влияют не только государства, но и ряд влиятельных компаний. Эти фирмы являются важнейшими элементами национальной экономической мощи, которые генерируют доходы, управляют торговлей и поддерживают научные исследования и разработки. В связи с появлением Китая в качестве экономической сверхдержавы, несколько китайских компаний поднялись в ранги, чтобы быть среди крупнейших в мире. Sinopec Group, State Grid, China National Petroleum, China State Construction Engineering, Ping An Insurance, Industrial and Commercial Bank of China компании, находящиеся в топе крупнейших за 2020 г. и их количество будет расти. Компании также можно сравнивать с точки зрения ценности бренда. Brand Finance ежегодно составляет рейтинг лучших мировых брендов, и в 2020 г. совокупная стоимость самых ценных китайских брендов составила 1,4 трлн. долл. США. Несмотря на то, что Китай достаточно хорош, чтобы занять второе место в мире, ведущие американские бренды могут похвастаться впечатляющей совокупной стоимостью в 3,2 трлн долл., также почти в три раза опережают Китай по количеству брендов в рейтинге Brand Finance: 205 американских брендов лидируют по сравнению с 75 китайскими [15]. Из этого следует, что китайские компании лидируют, но не являются абсолютно доминирующими.

Участие в международных организациях воспринимается как важный показатель престижа нации, а также как форум, через который нация может влиять на других и получать доступ к программам помощи, источникам технологий и информации. В первые два десятилетия своего существования Китайская Народная Республика была лишена возможности активно участвовать в большинстве основных международных организаций изза своего подчиненного положения в «китайско-советском» союзе в 1950-х и 1990-х гг. Противодействие США после участия Китая в Корейской войне не давало возможности для приема в ООН. В 1971 г. Пекин окончательно занял своё «кресло», когда отношения с Соединенными Штатами изменились к лучшему. К концу 1980-х гг. Китай стал членом нескольких сотен международных и региональных организаций, имеющих важнейшее значение для мировой политики, включая Международное агентство по атомной энергии, Всемирную организацию интеллектуальной собственности и Международный олимпийский комитет. Примечательно, что к концу 1980-х гг. Пекин не стремился официально вступить в ряд важных международных организаций, представляющих интересы Третьего мира: Группу 77, Движение неприсоединения и Организацию стран-экспортеров нефти. Несмотря на акцент, который Китай делал на отношениях с Третьими мирами, его независимая внешняя 
политика и особое положение в качестве несколько нетипичной страны Третьего мира делали маловероятным в конце 1980-х гг., что Китай будет стремиться к чему-то большему, чем статус наблюдателя в этих группах. Что касается 2020 г., то Китай является членом ВТО, который помогает Поднебесной наращивать экономическую мощь за счёт расширения торговли и привлечения ПИИ. Однако есть и минусы: КНР придется обновить свою правовую систему, чтобы соответствовать международным нормам, госпредприятия и государственные банки будут деструктурироваться, и иностранцы смогут выйти на многие рынки Китая, рост экономической свободы, несомненно, будет иметь свои последствия. КНР принимает активное участие в АТЭС, которое является мощным инструментом интеграции на азиатско-тихоокеанском пространстве. КНР также член МВФ, ей принадлежит 6,8 \% голосов в Совете управляющих МВФ и 10,92 \% приходится на китайский юань в корзине СДР в 2020 г. Также КНР - член Шанхайской организации сотрудничества, изначально создававшейся как политическая организация по борьбе с терроризмом. Сейчас она затрагивает экономические проблемы. Очевидно, что Китай взаимодействует с разными странами через организации, которые влияют на национальную экономику. Принадлежность к разным организациям - большой шаг на пути к миру и процветанию.

У каждой страны свои особенности развития, Китай не исключение. Можно выделить следующие элементы формулы успеха Китая: 1) повышение эффективности экономики; 2) улучшение состояния села. Чтобы накормить и одеть народ, искоренить бедность, нужно создать благоприятные условия для развития малого бизнеса. Нужно дать миллионам людей почувствовать себя нужными; 3) недопущение расхищения национального достояния. Важно сделать упор на привлечение иностранных инвестиций, образуя экономические зоны и предоставляя инвесторам разные льготы; 4) корректировать действия властей; 5) «трудостойкость» китайцев.

\section{ЗАКЛЮЧЕНИЕ}

Анализ социально-экономического развития экономики КНР показал, что даже в сложных условиях, имеющихся пока еще внутри страны, и вновь возникающих глобальных, страна сумела сохранить устойчивые темпы роста. Китай стал «мировой фабрикой» из-за сильной бизнес-экосистемы, низких налогов и пошлин, а также конкурентоспособной валютной практики. Участие Китая в международной экономике также открывает новые возможности для торговли, инвестиций и иных интеграций для содействия мировому процветанию и стабильности. Китайцы из года в год усердно работают на благо своей страны, добиваясь установленных целей, что не может вызывать восхищения.

\section{СПИСОК ЛИТЕРАТУРЫ}

1. Абрамкина, М. С. Политические риски китайского проекта «Один пояс, один путь» / М. С.Абрамкина // Экономические отношения. - 2018. - № 3.

2. Бергер, Я. М. Китайская модель глобализации / Я. М. Бергер // Век глобализации. 2009. - № 1. - С. 91-97.

3. Калашников, Д. Б. Китай в международном движении капитала / Д. Б. Калашников // Мировое и национальное хозяйство. - 2020. - № 4(53).

4. Каукенова, Т. Китай через 20 лет / Т. Каукенова // Forbes [Электронный ресурс]. URL: https://forbes.kz/process/expertise/kitay_cherez_20_let (дата обращения: 11.05.2021)

5. Мингазов, С. Экономика Китая выросла на рекордные 18,3 \% в первом квартале / C. Мингазов. [Электронный pecypc]. - URL: https://www.forbes.ru/newsroom/finansy-iinvesticii/426549-ekonomika-kitaya-vyrosla-na-rekordnye-183-v-pervom-kvartale (дата обращения: 11.05 .2021$)$

6. Панкратова, А. Е. Китайский фактор в Юго-Восточной Азии: влияние на международные экономические отношения в начале XXI века / А. Е. Панкратова // Экономические отношения. - 2018. - № 2. - С. 207-216. 
7. Самусенко, Д. Н. Инвестиционные стратегии китайских транснациональных корпораций / Д. Н. Самусенко // Экономические отношения. - 2018. - № 2. - С. 193-206.

8. Синьхуа: почему Китай по-прежнему является развивающимся государством? EKD [Электронный ресурс]. - URL: http://ekd.me/2018/06/sinxua-pochemu-kitaj-po-prezhnemuyavlyaetsya-razvivayushhimsya-gosudarstvom/ (дата обращения: 11.05.2021)

9. Chen Wu. China's Stimulus Package. A Six-Month Report Card // EIU. 2009. July. [Электронный pecypc]. - URL: WWW. bcecc.be/docs/200908079807_Stimulus\%20new\%20main\%20July2009.pdf （дата обращения: 11.05.2021)

10. Национальное бюро статистики Китая [Электронный ресурс]. - URL: http://www.stats.gov.cn/english/ (дата обращения: 5.05.2021)

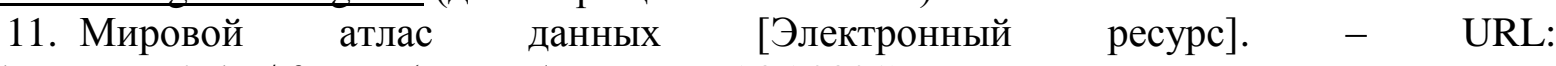
https://knoema.ru/atlas/Китай (дата обращения: 5.05.2021)

12. Официальный сайт Всемирного банка [Электронный ресурс]. - URL: https://www.worldbank.org/en/home (дата обращения: 5.05.2021)

13. Официальный сайт Всемирной торговой организации [Электронный ресурс]. URL: https://www.wto.org/ (дата обращения: 5.05.2021)

14. Портал экономических и финансовых данных [Электронный ресурс]. - URL: https://www.economicdata.ru/index.php (дата обращения: 5.05.2021)

15. Center for strategy\&international studies [Электронный pecypc]. - URL: https://chinapower.csis.org/chinese-companies-global-500/ (дата обращения 19.05.2021)

\title{
CHINA’S ECONOMY IN THE INTERNATIONAL ECONOMY
}

\author{
D. S. Rokina, student, \\ e-mail: dasharokina01@gmail.com \\ Kaliningrad State Technical University
}

\author{
A. A. Kotenko, PhD, Associate Professor, \\ e-mail: aljona.kotenko@klgtu.ru \\ Kaliningrad State Technical University
}

The article considers the change in the position of the Chinese economy in the world economy system. The paper analyzes the dynamics of indicators of China's socio-economic development over the past 30 years, examines the impact of China on international economic relations, describes methods of dealing with the crisis, and predicts the further development of China. The main focus is on the author's so-called "formula for success", which made China what it is now. The results of the study allowed the authors to draw a conclusion about the strengthening of China's position in the world economy. China, despite the difficult problems at home and the growing global uncertainty, has managed to maintain steady economic growth and continue to implement large-scale economic transformations. China's economy is showing positive changes in the area of structural reforms and the ability to keep risks under control, which helps the country to remain one of the fastest-growing economies in the world. The Chinese work hard for the good of their country year after year, achieving the set goals, which can not be admired.

Key words: new model of globalization, crisis, socio-economic indicators, GDP dynamics, capital movement, investment, foreign trade, international reserves, structure of the economy, tertiary sector, "formula for success" 